\title{
Association of Workplace Bullying and the Quality of Nursing Care in Intensive Care Unit and Emergency Department Nurses
}

\author{
Fatemeh Hajibabaee ${ }^{1}$, Seyed Hossein Mousavi ${ }^{2}$, Amin Hosseini ${ }^{3}$, Shima Haghani ${ }^{4}$, \\ Soheila Bahramali ${ }^{5}$
}

\begin{abstract}
Background \& Aims: The work environment of healthcare providers and hospitals is constantly exposed to tremendous work pressure, complexity, and chaos. Due to the changes in various fields of treatment and care, these work environments are constantly changing as well. Meanwhile, bullying is considered to be a serious phenomenon in these organizations, which has also been reported worldwide as an important issue in the nursing profession. Workplace bullying could variably affect nursing. In healthcare organizations, workplace bullying could increase absenteeism, job loss, and job dissatisfaction among the employees. Furthermore, this phenomenon may reduce the quality of nursing care in hospitals and medical centers. These issues are particularly highlighted in the nursing profession since as the largest group of healthcare providers in these organizations and the leading managers of hospitals, nurses play a pivotal role in patient care. Improving the quality of nursing care is the most important factor to accelerate the recovery and return of patients to the community; therefore, the quality assessment of nursing care is essential. In Iran, most of the studies on bullying have been performed on students and teachers in schools, and few studies have been focused on nurses. Given the lack of accurate statistics on the rate of workplace bullying among Iranian nurses and the fact that the quality of nursing care is an important issue that could be affected by the bullying phenomenon, the present study aimed to evaluate the level of workplace bullying among Iranian nurses and its association with the quality of nursing care.

Materials \& Methods: This cross-sectional, descriptive-correlational study was conducted on 200 emergency department and intensive care unit (ICU) nurses at Imam Khomeini Hospital Complex affiliated to Tehran University of Medical Sciences, Iran in 2019. The sample size included 200 nurses who were selected via simple random sampling. The inclusion criteria were employment as a nurse in the emergency department or ICU of Imam Khomeini Hospital Complex, willingness to participate in the study, and minimum work experience of six months as a nurse in the department. The exclusion criterion was incomplete questionnaires. Data were collected using a demographic questionnaire (age, gender, marital status, admission to the nursing major based on interest/knowledge, education level, clinical ward, service history, type of employment, shift work, duration of employment in the current department, having a managerial position, interest in the workplace, and coercion in the current department), negative acts questionnaire-revised, and SERVQUAL questionnaire. Sampling was performed after the approval of the study protocol and receiving the ethics license from the Joint Organizational Ethics Committee of the School of Nursing and Midwifery and the School of Rehabilitation of Tehran University of Medical Sciences. Eligible nurses were selected after explaining the research objectives and procedures and being assured of the confidentiality of their information with oral consent. The questionnaires were completed anonymously and in a self-report manner. Data analysis was performed in SPSS version 16 using descriptive statistics to describe the samples (frequency distribution tables, mean, and standard deviation). In addition, research objectives were used to describe the samples. To determine the gap between the perceptions and expectations regarding the quality of nursing care, paired t-test was used, and to determine the correlation between

\footnotetext{
1. Department of Critical Care Nursing and Management, School of Nursing and Midwifery Tehran University of Medical Sciences, Tehran, Iran

2. Department of Psychiatric Nursing School of Nursing and Midwifery, Tehran University of Medical Sciences, Tehran, Iran

3. MS Student in Medical-Surgical Nursing, School of Nursing and Midwifery, Tehran University of Medical Sciences, Tehran, Iran (Corresponding author) Tel: 09303052417 Email: Ahosseinis@ razi.tums.ac.ir

4. Biostatistics, Nursing Care Research Center, Iran University of Medical Sciences, Tehran, Iran

5. Nursing Office, Imam Khomeini Hospital Complex, Tehran University of Medical Sciences, Tehran, Iran
} 
workplace bullying and the quality of nursing care, Pearson's correlation-coefficient was employed at the significance level of 0.05 .

Results: About half of the nurses (51.5\%) were female, with the mean age of $32.58 \pm 6.38$ years. The mean work experience of the subjects was $9.74 \pm 5.86$ years in the nursing profession and $4.59 \pm 3.99$ years in their current ward of employment. The majority of the nurses (51\%) were formally employed, had rotating work shifts (77\%), and worked in the ICU (61.5\%). In addition, most of the nurses had a BSc degree (84.5\%). Based on the experience of daily or weekly workplace bullying, the mean workplace bullying of the nurses in the work-related bullying dimension was $10.11 \%$, while it was $4.27 \%$ in the person-related dimension, and $5.66 \%$ in the physical dimension, with an overall mean of $6.68 \%$. The maximum and minimum mean values belonged in the dimensions of workrelated bullying and physical dimension, respectively. The results of paired t-test indicated significant differences between the dimensions of the perceptions, expectations, and gaps in the quality of nursing care in the viewpoint of the nurses and the dimensions of reliability $(\mathrm{P}<0.001)$, assurance $(\mathrm{P}<0.001)$, and total score $(\mathrm{P}<0.001)$. Furthermore, workplace bullying had inverse, significant correlations with the dimensions of reliability $(\mathrm{P}=0.006$; $\mathrm{r}=-0.194)$ and assurance of nursing care quality $(\mathrm{P}=0.001 ; \mathrm{r}=-0.229)$, so that with decreased workplace bullying, the quality of nursing care increased in these dimensions.

Conclusion: Although the results of this study indicated the low prevalence of bullying among nurses, nursing managers and policymakers should properly plan for the recognition, prevention, and management of this phenomenon due to the physical, psychological, and organizational effects of workplace bullying on the nurses employed in hospitals and health centers. Moreover, the organizational factors that lead to the workplace bullying of nurses should be identified. Due to the significant associations between workplace bullying and the dimensions of the reliability and quality assurance of nursing care, hospitals must fulfill their promises accurately and consistently. By recruiting nurses with adequate knowledge and skills, a sense of trust and confidence should be created in patients. This study showed that the lower rate of workplace bullying is associated with the higher quality of nursing care. Therefore, it is recommended that further investigations be focused on the effects of workplace bullying on patient care and its dimensions, as well as the quality of the provided care in hospitals and health centers.

Keywords: Bullying, Workplace, Nursing, Nursing Services

\section{Conflict of Interest: No}

How to Cite: Hajibabaee F, Mousavi SH, Hosseini A, Haghani SH, Bahramali S. Association of Workplace Bullying and the Quality of Nursing Care in Intensive Care Unit and Emergency Department Nurses. Iran Journal of Nursing. 2020; 33(125):42-54.

Received: 9 May 2020

Accepted: 9 Aug 2020 


\section{ارتباط بين زورَّويى در محيط كار برستاران با كيفيت خدمات برستارى در برستاران شاغل در بخشهاى مر اقبتهاى ويزه و اورزانس}

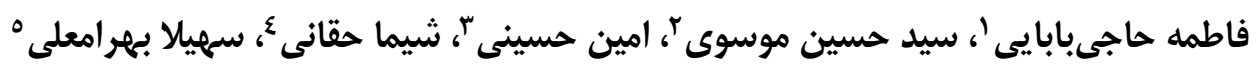

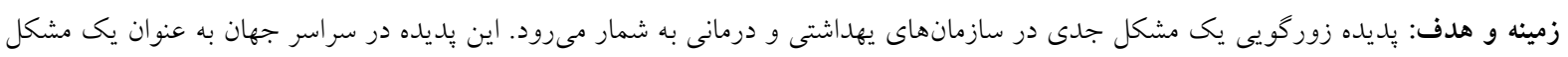

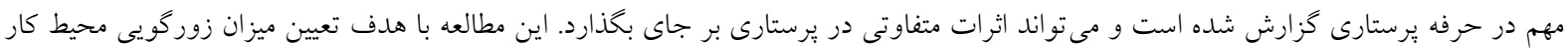

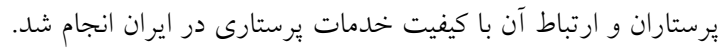

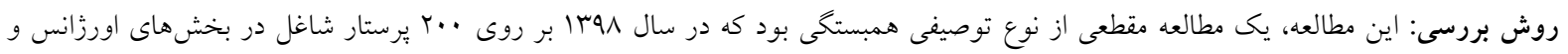

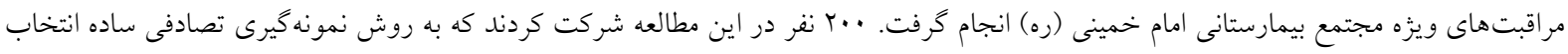

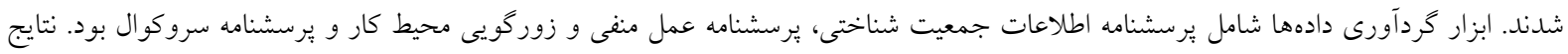

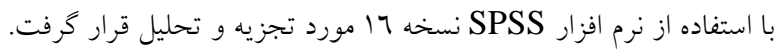

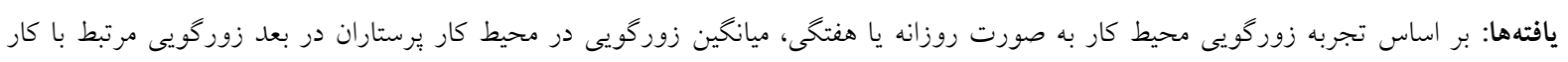

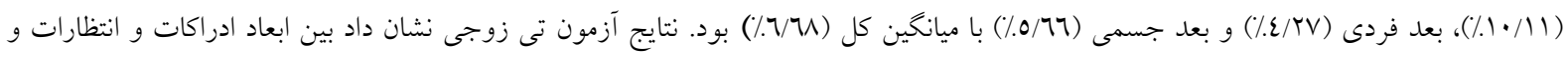

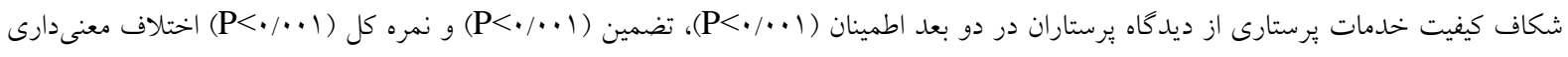

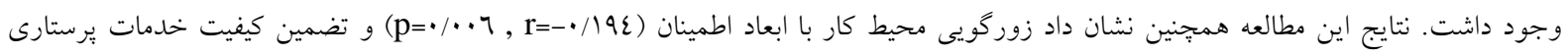

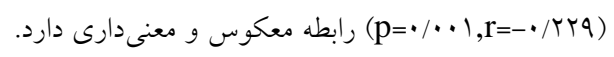

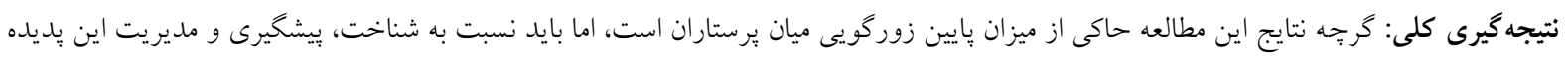

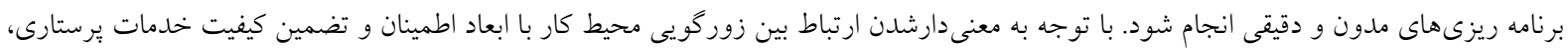

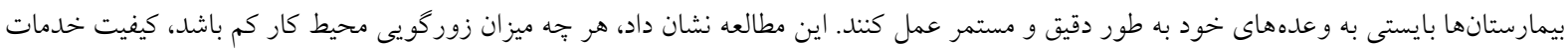

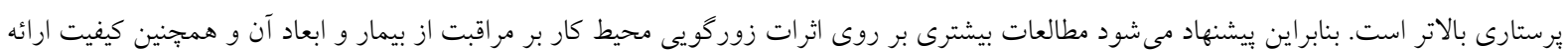
اين مراقبتها در بيمارستانها و مراكز بهداشتى - درمانى انجام كيرد.

كليد وازهها: زور گويى، محيط كار، يرستارى، خدمات يرستارى تعارض منافع: ندارد تاريخ دريافت: • تاريخ بذيرش: 99/0/19

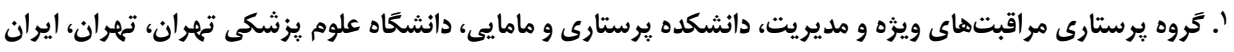

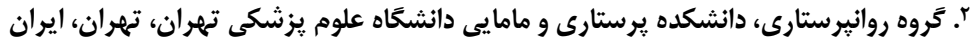

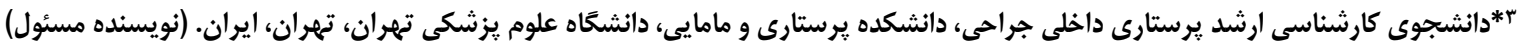
Email:Ahosseinis@ razi.tums.ac.ir شماره تماس:

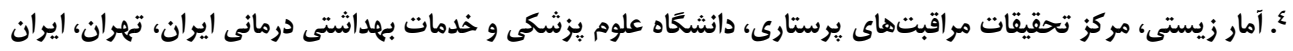

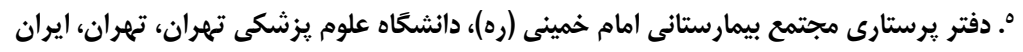


كردهاند (^). در آمريكا، س TV/T درصد يرستاران اورزانس تجربه مواجه شدن با زوركويى محيط كار را داشتهاند.

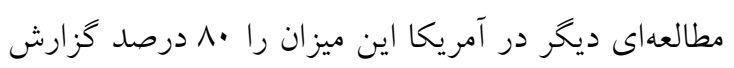

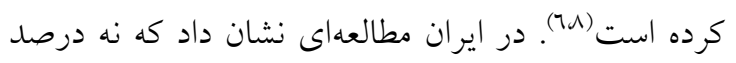
يرستاران مكرراّ، زوركويى محيط كار را تجربه مى كنند (9).

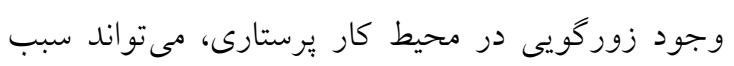

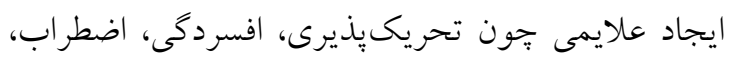

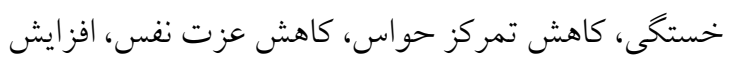

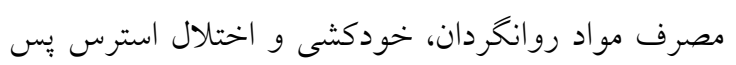

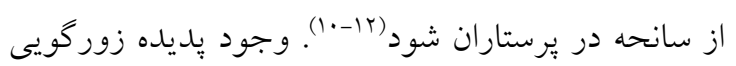

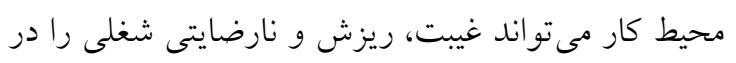
ميان كاركنان افزايش دهد. تحقيقات حاكى از آنند كه فشار

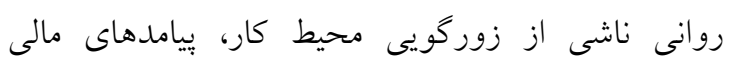

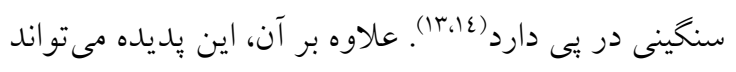

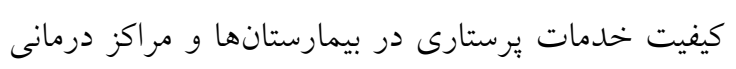
را كاهش دهد (1). اين در حالى است كه اساساً كيفيت ارائه

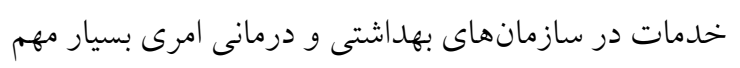
تلقى مىشود. بر مبناى فلسفه وجودى اين سازمانها كه نياز مردم به حفظ سلامت مىباشد و از آنجاكه مقوله بنه سلامت نيز امرى خطير و حساس است كه با جان انسان ها سر و كار دارد، كيفيت خدمات در اين حوزه بسيار

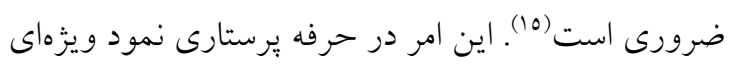

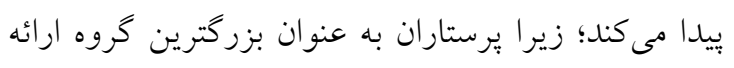

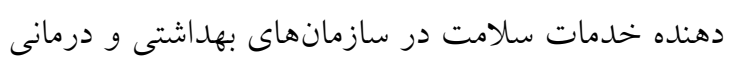

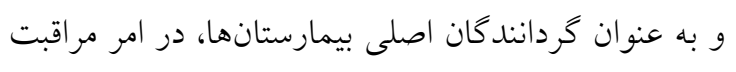

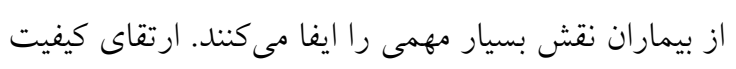

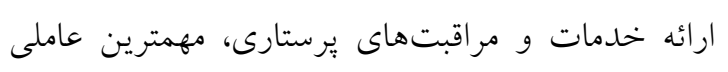

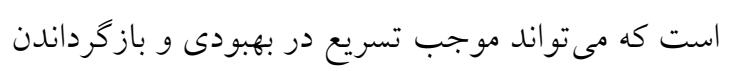

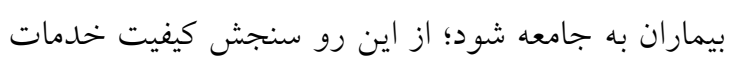

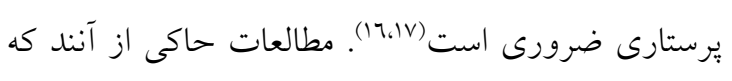

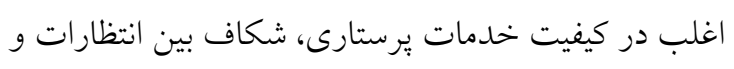

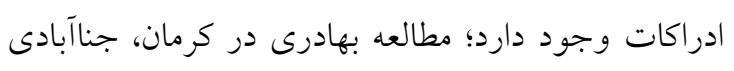
در زاهدان و استكى در اصفهان مؤيد اين واقعيت هستند.

\section{مقلهمه}

زورگويى در محل كار تركيبى از سياست هايى است كه در آن شمار زيادى از رفتارهاى مكرر، به صورت توريى دورين

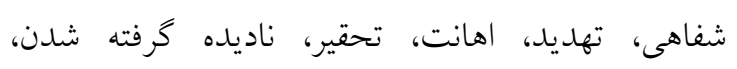
ترساندن، كارشكنى و خر ابكارى و يا تركيبى از جند رفتار رخ مى دهد. وازه "زور گويى "در كشورهاى مختلف باو وازه هايى نظير خشونت، بى تمدنى، بحث و جدل، آزار، اذيت،

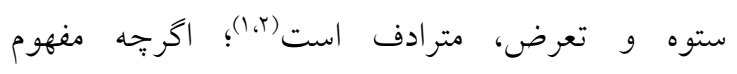
"خشونت" با زوركويى متفاوت است، زيرا خشونت در

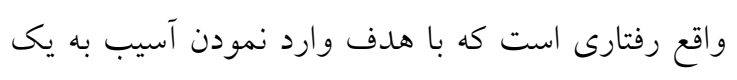

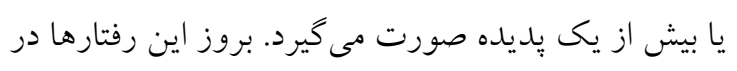

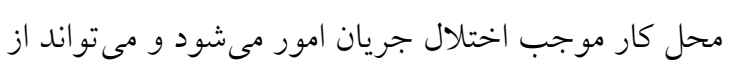
طرف همكار و مافوق به صورتهاى افقى، عمودى و ماتريكسى رخ دهد (ع،ب). محيط كار سازمانهاى ارائهدهنده خدمات سامت وهات و بيمارستانها همواره در معرض فشار باريط بالاى كارى، يبيجيدگى و هرج و مرج بوده و به دليل تحولات در زمينه

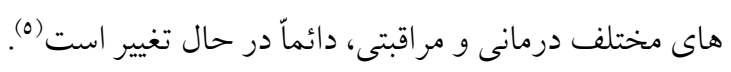
در اين ميان بِديده زورگويى يك مشكل جدى درى در اين

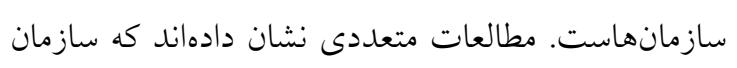
هاى بهداشتى و درمانى از جمله محيطهاى كارى هستند

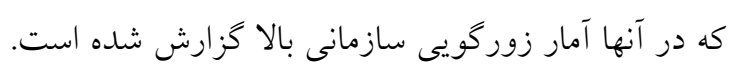

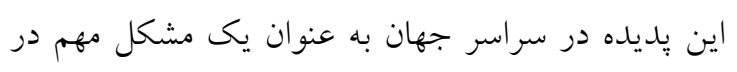

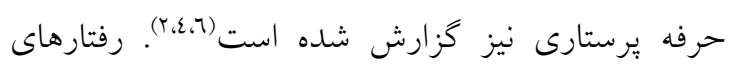

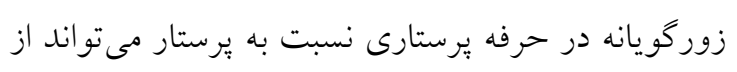

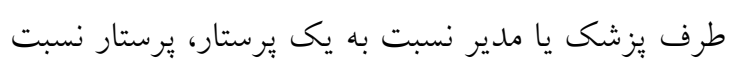

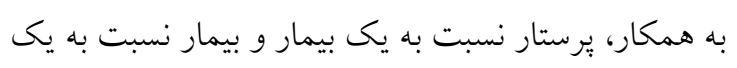

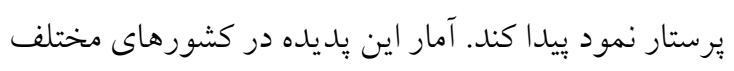
به دلايلى جون تفاوت معنايى، طراحى مطالعات، مسائل

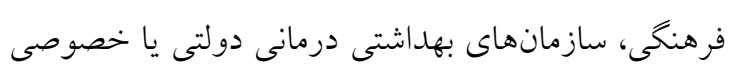

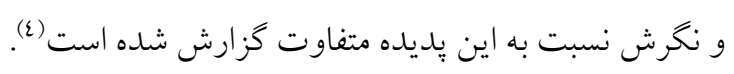
مطالعهاى در تركيه نشان داده كه 10/7 درصد يرستاران، زورگويى محيط كار را تجربه كردهاند (v). در انخلستان از

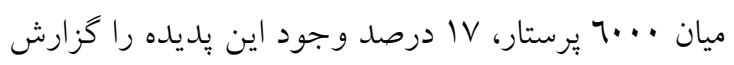


نفر بود. براى تعيين حجم نمونه در سطح اطمينان 90

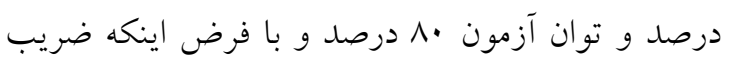

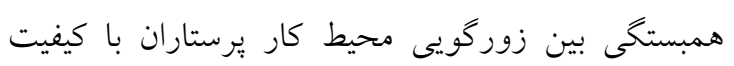

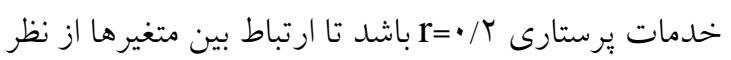

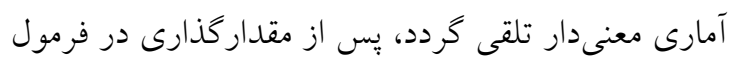
حجم نمونه برآورد كرديد.

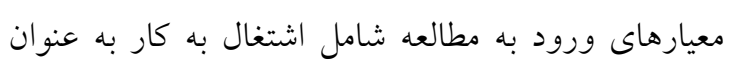

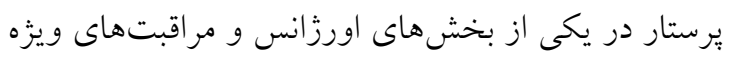

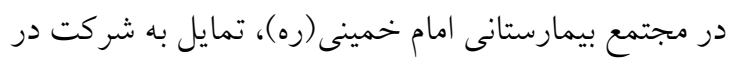
مطالعه و داشتن حداقل شش ماه سابقه كارى به عنوان يرستار در آن بخشها و معيارهاى خروج از مطالعه شامل تكميل ناقص يرسشنامها توسط واحدهاى مطالعه در نظر كرفته شد. در اين مطالعه بر اساس ليست اسامى برستاران شاغل در بخشهاى اورزانس، مراقبتهاى ويزه و دياليز در دفتر يِرستارى، به تعداد مورد نظر، از يُرستارانى كه

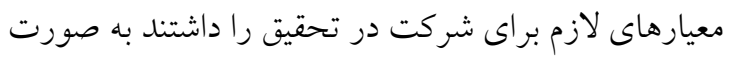

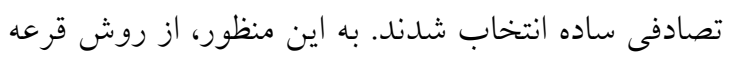

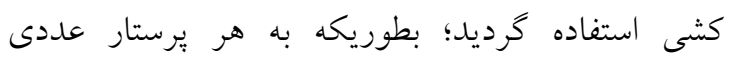

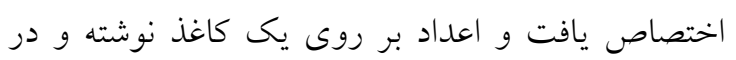

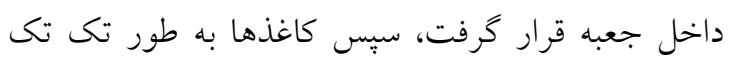

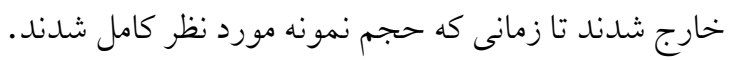

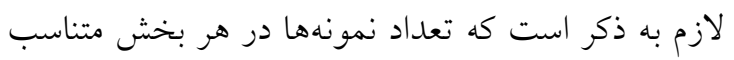

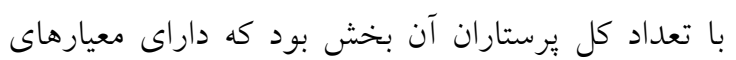

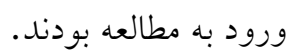

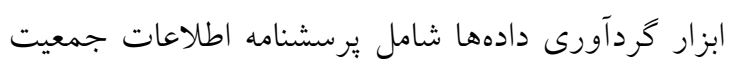

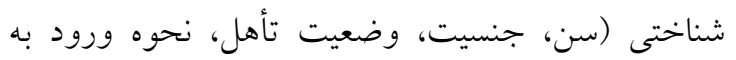

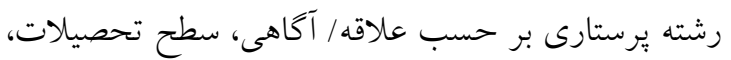

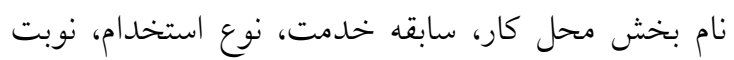

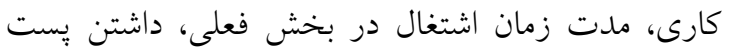

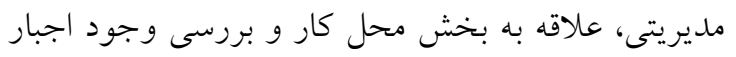

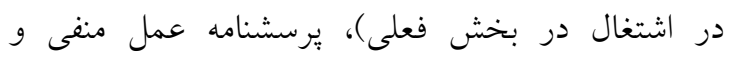
زورگويى محيط كار (Negative Acts = NAQ-R Questionnaire - Revised

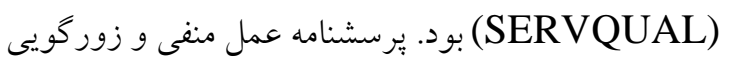

محققين اشاره داشتهاند اين موضوع در كشورهاى جهان نيز صادق بوده است (17).

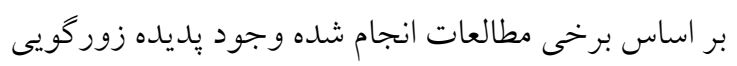

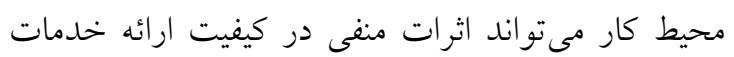

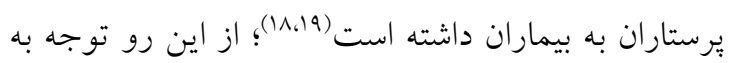

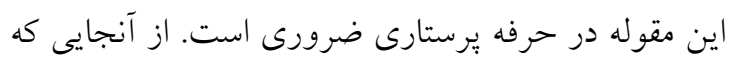

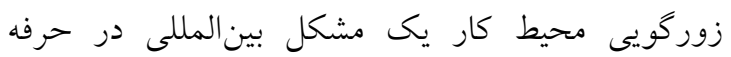
يرستارى است، تحقيقات متعلدى در كشورهاى مختلف دنيا از جمله كانادا، انخلستان، امريكا، استراليا، نيوزلند،

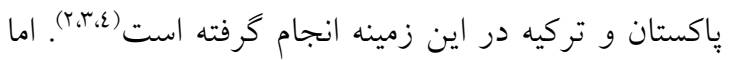

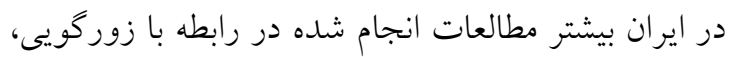
بر روى دانش آموزان و معلمان در مدارس صورت كَفته و مطالعات اندكى در اين زمينه بر روى يرستاران انجام شده است. با توجه به اينكه آمار دقيقى درباره ميزان

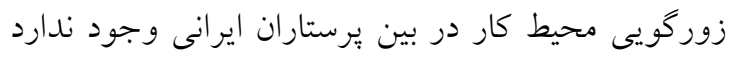

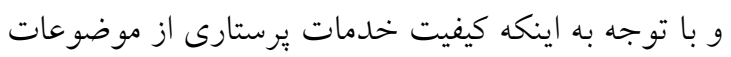

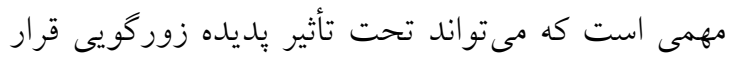

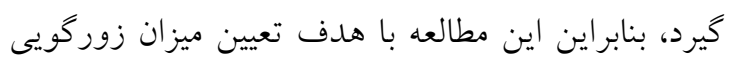

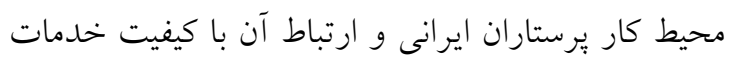

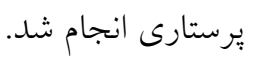

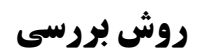

اين مطالعه، يك مطالعه مقطعى از نوع توصيفى همبستخى دورى دونى

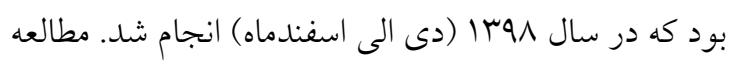

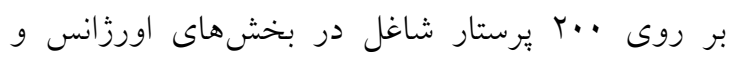

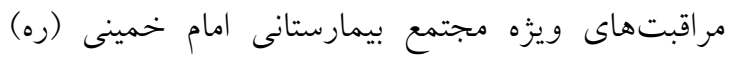

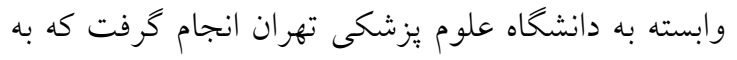

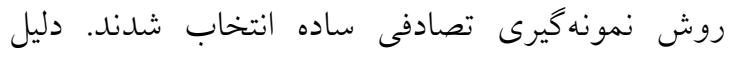
انتخاب اين بخشهاى بالينى، مستعدتر بودن يرستاران

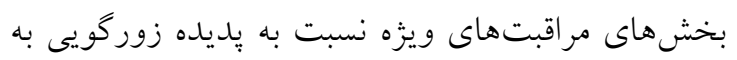

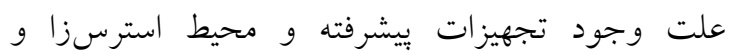
همجنين حجم و فشار كارى بالا در بخش اورزانس بود.

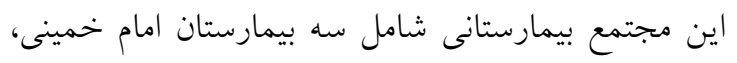

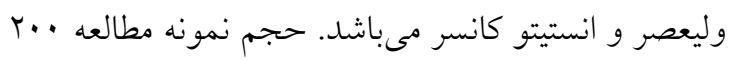


مى دهد. سؤالات يرسشنامه بر اساس مقياس بنج كزينهاى

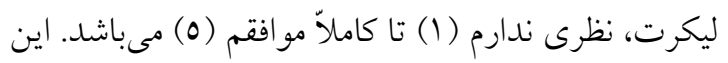

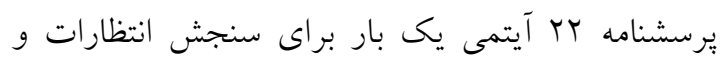

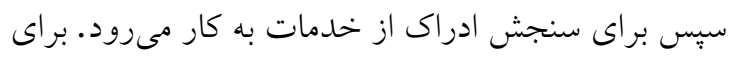

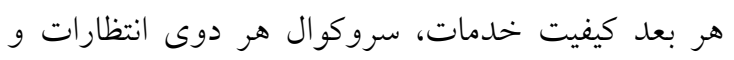

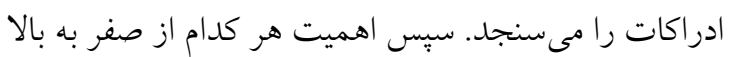
بر اساس نمره مشخص مىشوند. شكاف نمرات بر اساس اختلاف نمره دو دسته سؤالات مربوط به انتظارات و ادراكات محاسبه مىشود. نمره منفى نشان مىدهد كه

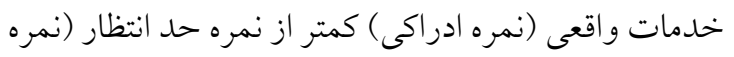

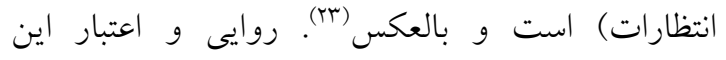
يرسشنامه قبلاً در مطالعه استكى و عطافر مورد تأييد قرار

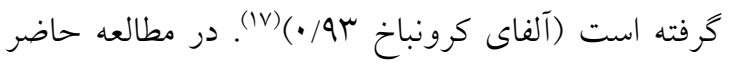

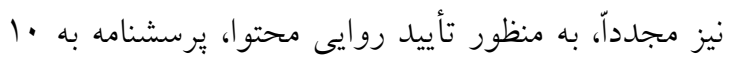

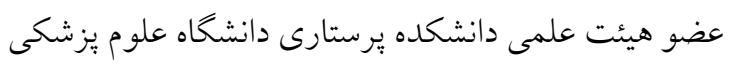

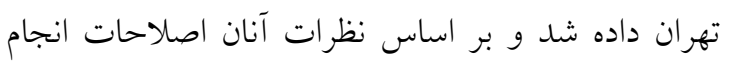

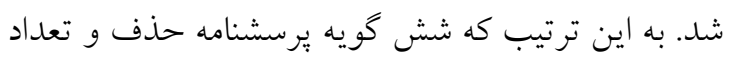

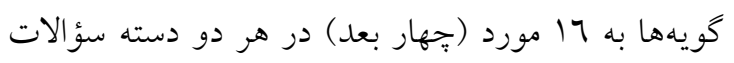

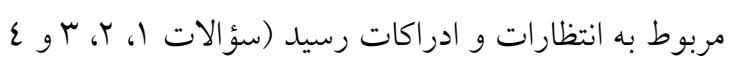

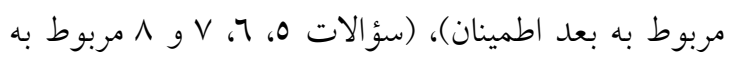

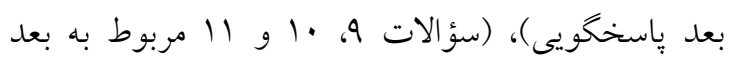

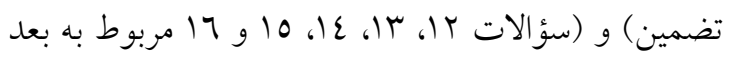

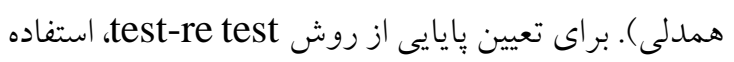

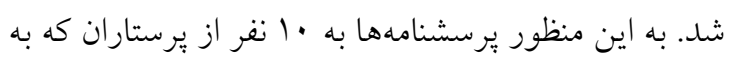
روش تصادفى انتخاب شده بودند، داده شد. مجلدداً بعد از

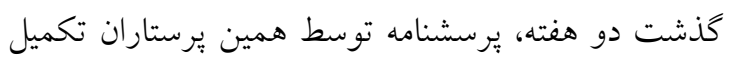

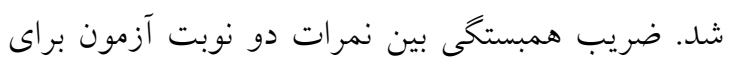

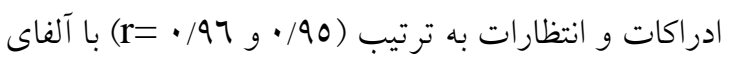

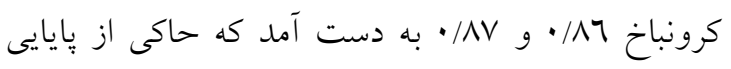

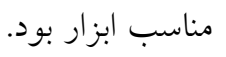

يس از تصويب طرح و دريافت مجوز اخلاق از كميته

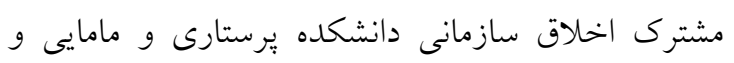
دانشكده توانبخشى دانشكاه علوم يزشكى تهران

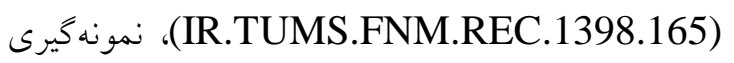

در محيط كارى با ب سؤال در سال IT I ابتدا توسط

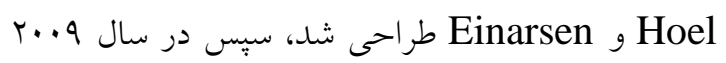

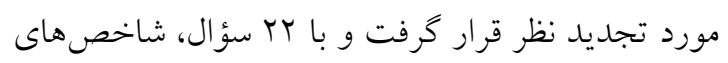

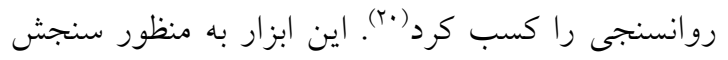

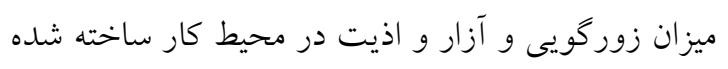

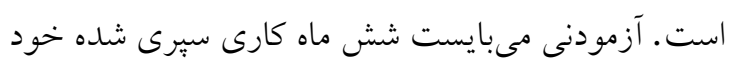

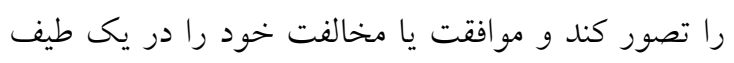

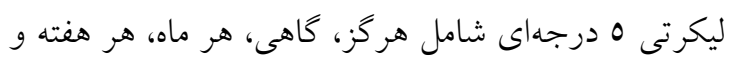

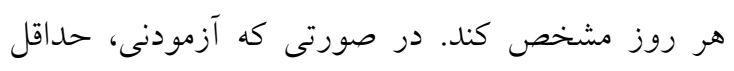

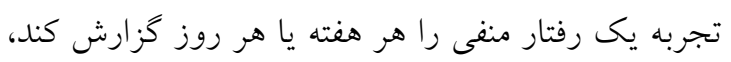

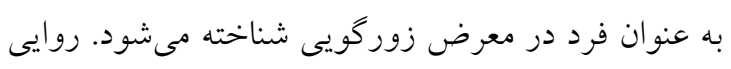

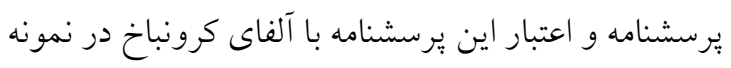

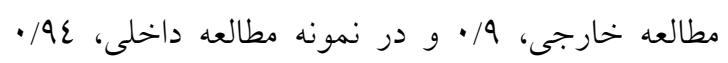

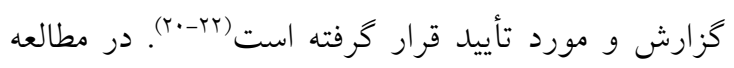

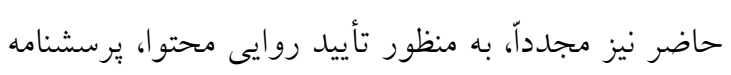

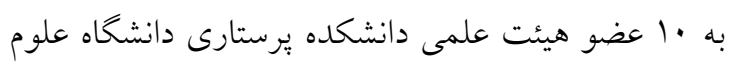

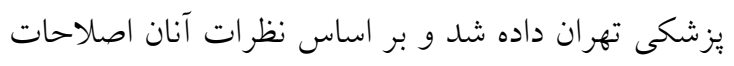

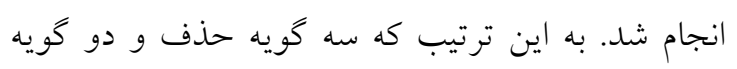

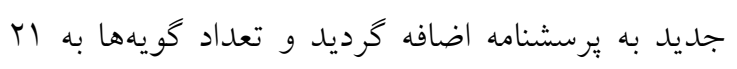

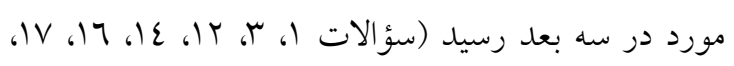

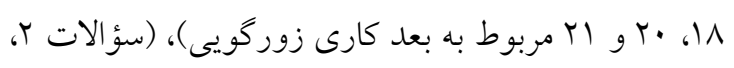

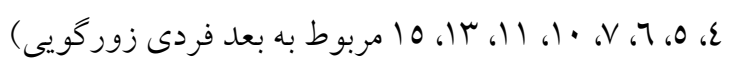

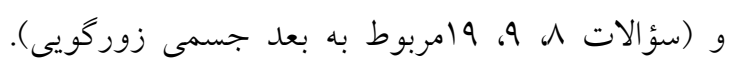

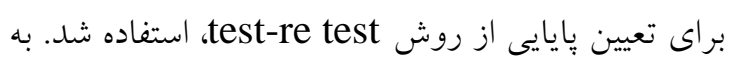

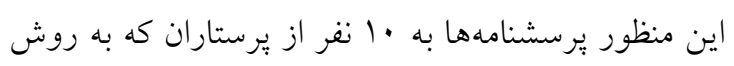

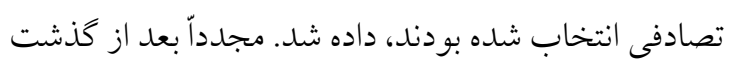
دو هفته، يُرسشنامه توسط همين يرستاران تكميل شده. ضريب همبستخى بين نمرات دو نوبت آزمون (r=/AY)

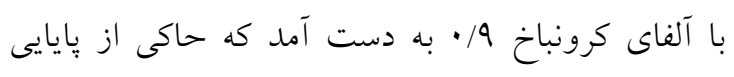
مناسب ابزار بود. يرسشنامه سروكوال براى سنجش كيفيت خدمات حاوى برى بود

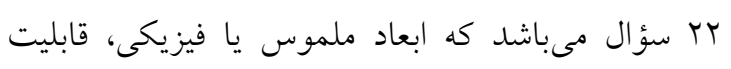

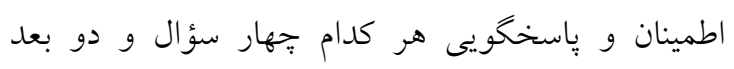

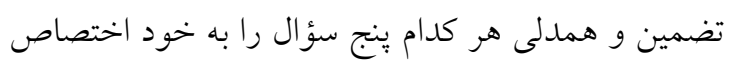




\section{يافتهها}

بر اساس نتايج مطالعه، حدود نيمى از يرستاران شركت

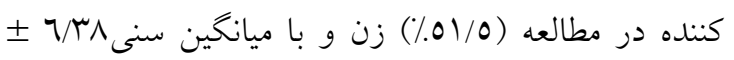
Mr/ON

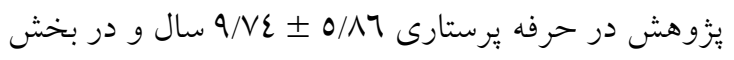

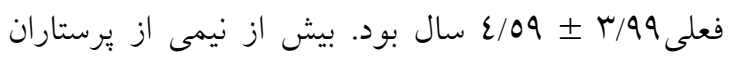

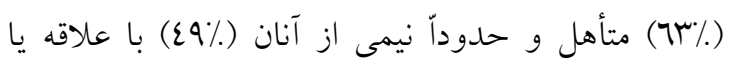
آكاهى وارد حرفه برستارى شده بودند. نيمى از برستاران

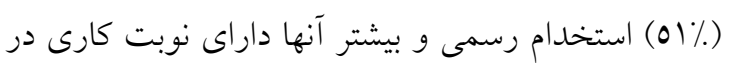

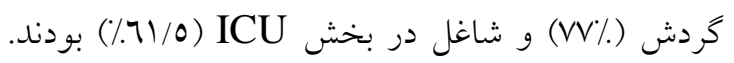

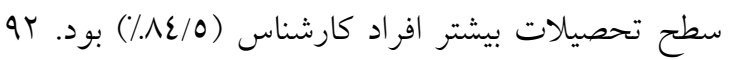
درصد از يرستاران به بخش محل كار خود علاقه داشته و

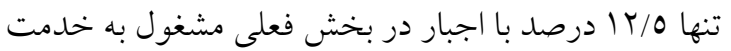

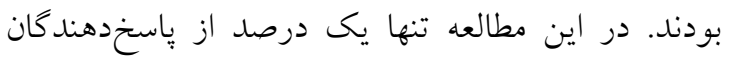
سويروايزر و دو درصد سريرستار بودند (جدول شماره ()).
انجام شد. بدين صورت كه يرستار ان داراى معيارهاى ورود

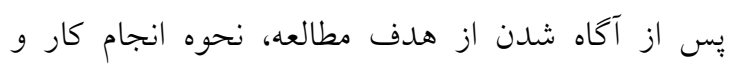
محرمانه ماندن اطلاعات با كسب رضايت شفاهى و بدون

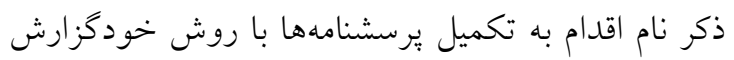

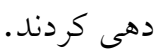
داده ها با استفاده از نرم افزار SPSS نسخه 17 و و آمار توصيفى و تحليلى مورد تجزيه و تحليل قرا كرفت. در اين

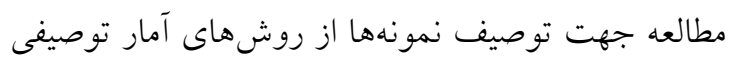
شامل جداول توزيع فراوانى، تعيين ميانخين، انحر اف معيار

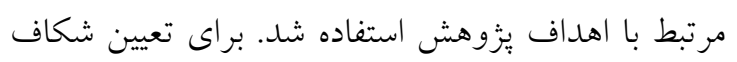

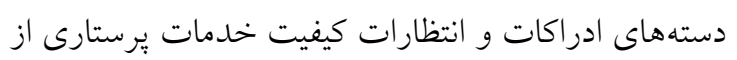
آزمون تىزوجى و براى تعيين رابطه بين زوركويى محيط ادراكي

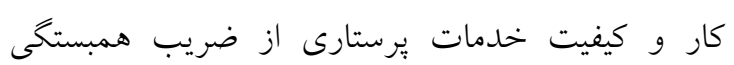

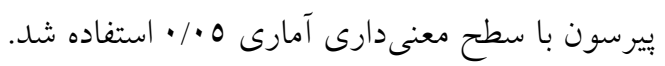

\begin{tabular}{|c|c|c|}
\hline Mean (SD) & \multicolumn{2}{|c|}{ اطلاعات جمعيت شناختى } \\
\hline 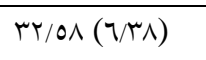 & & سن، سال" \\
\hline $9 / 2 \varepsilon(0 / 17)$ & & سابقه كار، سال" \\
\hline$\varepsilon / 09(r / 99)$ & & سابقه كار در بخش فعلى، سال" \\
\hline فراوانى (درصد) & مرد & \\
\hline $9 \vee\left(\sum \wedge / 0\right)$ & & جنسيت" \\
\hline $1 . r(01 / 0)$ & زن ان & \\
\hline$r \cdot(1 \cdot \cdot)$ & جمع كل & \\
\hline$V \varepsilon(Y V)$ & مجرد & \\
\hline $\operatorname{lrT}(7 r)$ & متأهل & " وضعيت تأهل "*" \\
\hline$r \cdots(1 \cdots)$ & جمع كل & \\
\hline m (IN) & با آكاهى & \\
\hline$\pi(r)$ & با علافه & نحوه ورود به حرفه" "*" \\
\hline $1 . r(01)$ & ساير س & \\
\hline$r \cdot(1 \cdots)$ & جمع كل & \\
\hline $179(\wedge \varepsilon / 0)$ & كارشناسى & \\
\hline$\mu_{1}(10 / 0)$ & كارشناسى ارشد & تحصيلات"" \\
\hline$r_{\cdots} \cdot(1 .)$. & جمع كل & \\
\hline$\varepsilon 1(T \cdot / 0)$ & اورزانس & بخش محل خدمت" "ب \\
\hline$r \varepsilon(I T)$ & $\mathrm{CCU}$ & \\
\hline
\end{tabular}




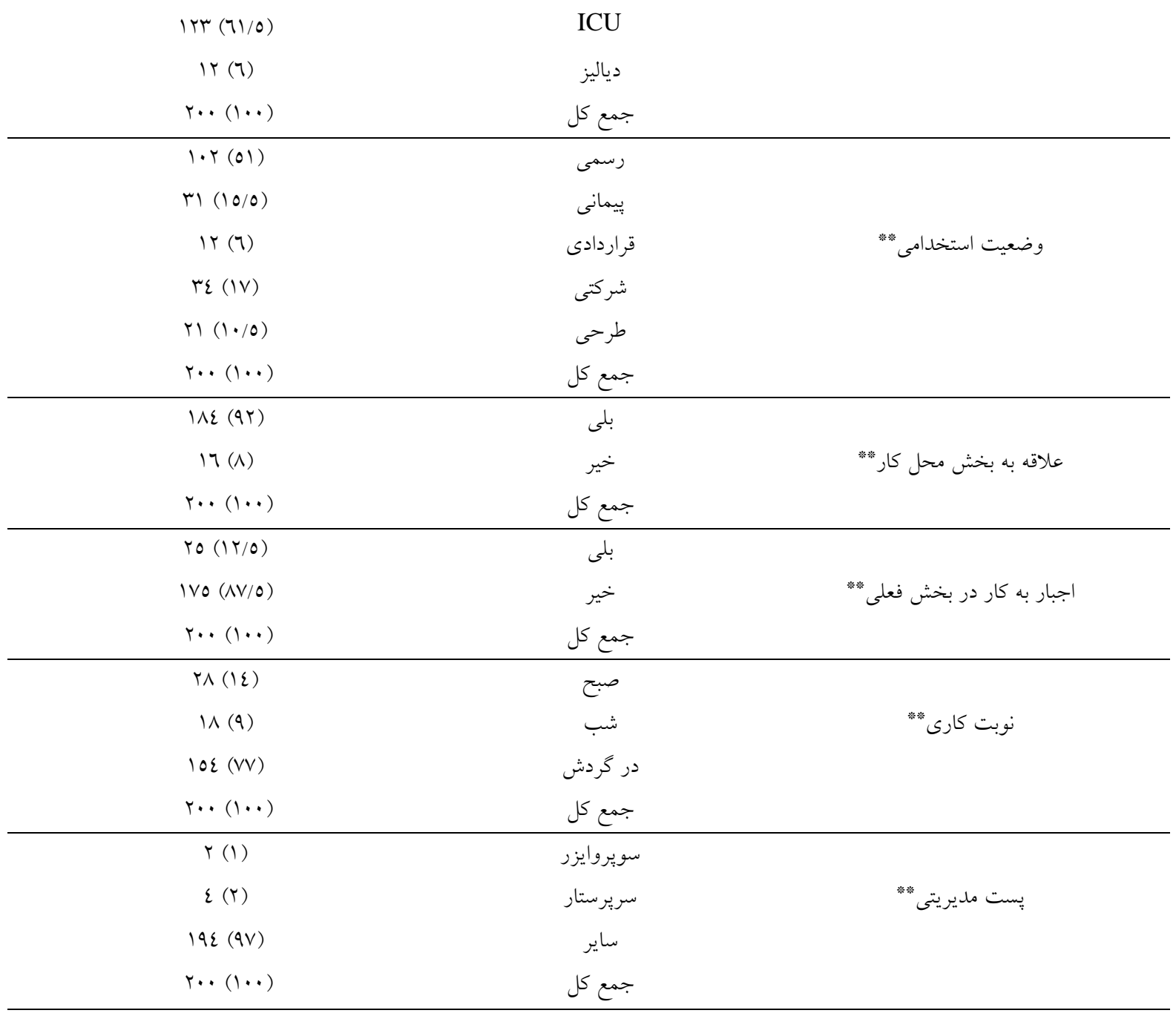

"ميانكين (انحراف معيار) "*" فراوانى (درصد)

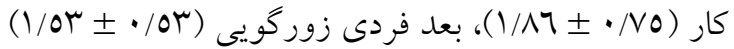
و بعد جسمى (1/7/ • 1/21) بود. همانطور كه مشاهده

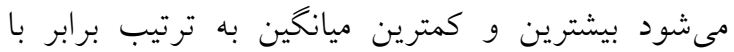
بعدهاى زورگويى مرتبط با كار و بعد جسمى زوركويى

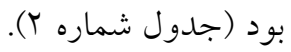

ميانخين درصد زوركويى در محيط كار يرستاران در بخش هاى اورزانس و مراقبتهاى ويزه در بعد زوركويى مرتبط با كار 11\% •11، بعد فردى زوركويى و بعد جسمى با ميانگين كل ب/7/7 بود. ميانخين كل نمرات زوركويى

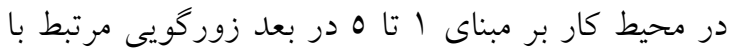

جدول شماره r: توزيع فراوانى عمل منفى و زورتويى در محيط كارى يرستاران

\begin{tabular}{|c|c|c|c|c|c|c|}
\hline معيار) بر مبناى انتين (انحر اف & (ميانخين درصد) & (ميانغين درصد يكبار & 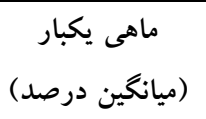 & (ميانغين درصى اوقات & (ميانخين درصد ) هيجوقت & ابعاد زوركويى \\
\hline $1 / 17(\cdot / \vee 0)$ & $7 / 0$ & $r / 71$ & $\tau / \mu$ & rT/VT & $\varepsilon \mathrm{T} / \mathrm{V}$ & زورگويى مرتبط با كار \\
\hline $1 / 0 r(\cdot / 0 r)$ & $1 / 71$ & $r / 77$ & $7 / \pi r$ & $r 7 / \mathrm{VV}$ & $7 r / 71$ & بعد فردى زوركويى \\
\hline $1 / 21(\cdot / 71)$ & $1 / 77$ & $\varepsilon / \cdot$ & $r / \mu r$ & $17 /$. & Vo/. & بعد جسمى زورگويى \\
\hline
\end{tabular}


انتظارات و شكاف كيفيت خدمات بِرستارى از ديدگاه يرستاران در دو بعد اطمينان ( (P</ (P)، تضمين

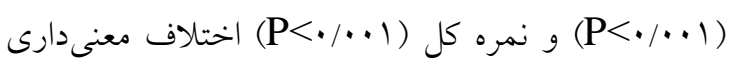

$$
\text { وجود داشت (جدول شماره r). }
$$

ميانخين شكاف بين دستههاى ادراكات و انتظارات كيفيت

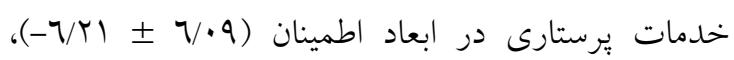

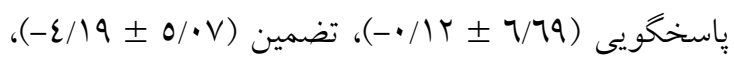
همدلى (1/99 بود. نتايج آزمون تىزوجى نشان داد بين ابعاد ادراكات و

جدول شماره س: بررسى بين ابعاد ادراكات و انتظارات و شكاف كيفيت خدمات يرستارى از ديدكاه يرستاران

\begin{tabular}{|c|c|c|c|c|c|c|c|}
\hline \multirow{2}{*}{$\frac{\text { آزمون تى زوجى }}{\text { P - value }}$} & \multicolumn{2}{|c|}{ شكاف } & \multicolumn{2}{|c|}{ ادراكات } & \multicolumn{2}{|c|}{ انتظارات } & \multirow[t]{2}{*}{ ابعاد } \\
\hline & انحر اف معيار & ميانخين & انحراف معيار & ميانخين & انحراف معيار & ميانخين & \\
\hline$<\bullet / \cdots)$ & $7 / 9$ & $-T / Y I$ & $0 / 27$ & $1 N / 7 \varepsilon$ & $\Gamma / \varepsilon V$ & $r \varepsilon / \wedge O$ & اطمينان \\
\hline - NAY & $7 / 79$ & $-\cdot / 1 T$ & $\varepsilon / \wedge \vee$ & $10 / \varepsilon \varepsilon$ & $0 / 0$. & $10 / 70$ & ياسخخويى \\
\hline$<\cdot / \cdots)$ & $0 / \cdot V$ & $-\varepsilon / 19$ & $r / v 7$ & $|\varepsilon / \mu|$ & $r / r \Lambda$ & $11 / 0$ & تضمين \\
\hline$\cdot / \varepsilon V$ & $1 / 99$ & $-\cdot / 27$ & $V / I V$ & $r \cdot / r \Lambda$ & $V / \pi I$ & $r \cdot / v \varepsilon$ & همدلى \\
\hline$<\cdot / \cdots)$ & $1 \mathrm{~V} / \varepsilon \varepsilon$ & $-1 \cdot / 91$ & $1 \pi / \cdot \varepsilon$ & $u / u$ & $\mid r / \varepsilon \Lambda$ & $\vee 9 / 77$ & كل \\
\hline
\end{tabular}

و و همدلى (p=•/ مستقيم و معنى دارى بود. بعد فردى زورگويى با ابعاد تضمين ( $)$ داراى ارتباط معكوس و معنى 2 مارى و بعد

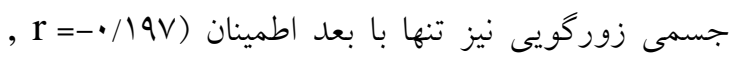

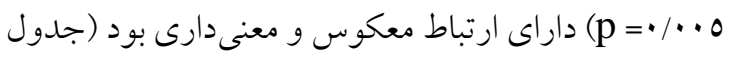

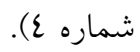

نتايج آزمون همبستخى بيرسون نشان داد زورگويى محيط

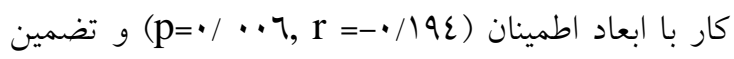

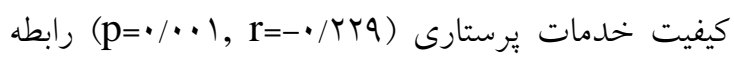
معكوس و معنى دارى دارد. بطوريكه هر مقدار ميزان زورگويى محيط كار كاهش مىيابد، سطح كيفيت خدمات يرستارى در اين ابعاد بالاتر مىباشد. بعد زوركويى مرتبط

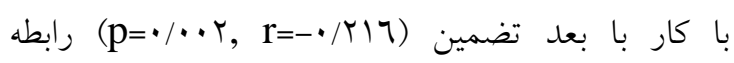

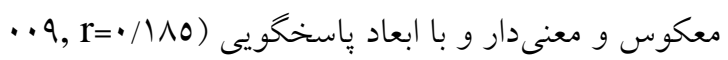

جدول شماره ع: ارتباط بين زور كويى محيط كار با كيفيت خدمات يرستارى و ابعاد آن

\begin{tabular}{|c|c|c|c|c|c|}
\hline $\begin{array}{c}\text { كل } \\
\text { (r, P - value) }\end{array}$ & $\begin{array}{c}\text { همدلى } \\
\text { (r, P - value) }\end{array}$ & $\begin{array}{c}\text { تضمين } \\
\text { (r, P - value) }\end{array}$ & $\begin{array}{c}\text { پاسخخويى } \\
\text { (r, P - value) }\end{array}$ & $\begin{array}{c}\text { اطمينان } \\
\text { (r, P - value) }\end{array}$ & ابعاد زوركويى \\
\hline $\mathrm{r}=\cdot / \cdot 79$ & $\mathrm{r}=\cdot / \mathrm{r} \cdot \cdot$ & $\mathrm{r}=-\cdot / r 17$ & $\mathrm{r}=\cdot / 1 \wedge 0$ & $\mathrm{r}=-\cdot / \mathrm{rr}$ & زورگويى مرتبط با كار \\
\hline $\mathrm{p}=\cdot \pi \mu r$ & $\mathrm{p}=\cdot / \cdots \varepsilon$ & $\mathrm{p}=\cdot / \cdot \cdot r$ & $\mathrm{p}=\cdot / \cdot \cdot \mathrm{q}$ & $\mathrm{p}=\cdot / \cdot \wedge 7$ & \\
\hline$r=-\cdot / / r_{1}$ & $\mathrm{r}=\cdot / \cdot r \varepsilon$ & $\mathrm{r}=-\cdot / r 01$ & $\mathrm{r}=\cdot / \cdot \varepsilon r$ & $\mathrm{r}=-\cdot / r \varepsilon \Lambda$ & بعد فردى زوركويى \\
\hline $\mathrm{p}=\cdot / \cdot 70$ & $\mathrm{p}=\cdot / N r \varepsilon$ & $\mathrm{p}<\cdot / \cdot \cdot 1$ & $\mathrm{p}=\cdot / 0 \varepsilon r$ & $\mathrm{p}<\cdot / \cdot \cdot)$ & \\
\hline$r=-\cdot / 11 \varepsilon$ & $r=-\cdot / \cdot \varepsilon q$ & $\mathrm{r}=-\cdot \cdot / \cdot \mathrm{v} 7$ & $\mathrm{r}=\cdot / \cdots 0$ & $r=-\cdot / 19 \mathrm{~V}$ & بعد جسمى زورگويى \\
\hline $\mathrm{p}=\cdot / 1 \cdot \wedge$ & $\mathrm{p}=\cdot / \varepsilon q \varepsilon$ & $\mathrm{p}=\cdot / \Upsilon \wedge \uparrow$ & $\mathrm{p}=\cdot / 9 \varepsilon 1$ & $\mathrm{p}=\cdot / \cdot \bullet$ & \\
\hline$r=-\cdot / \cdot r$. & $r=\cdot / 11 r$ & $\mathrm{r}=-\cdot / r Y q$ & $\mathrm{r}=\cdot / \mathrm{r}$. & $r=-\cdot / 19 \varepsilon$ & كل \\
\hline $\mathrm{p}=\cdot /$ TV $\mathrm{r}$ & $\mathrm{p}=\cdot / 11 \mathrm{r}$ & $\mathrm{p}=\cdot / \cdots 1$ & $\mathrm{p}=\cdot / .91$ & $\mathrm{p}=\cdot / \cdot \cdot 7$ & \\
\hline
\end{tabular}


و مديريت زوركويى محيط كار سبب شده تا ميزان اين

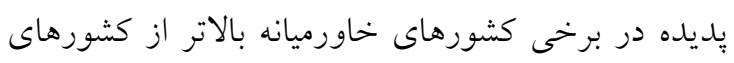

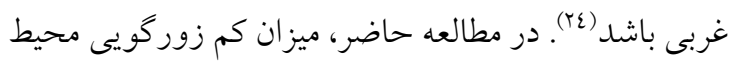
كار يرستارى مىتواند مربوط به محيطهاى كارى مطالعه

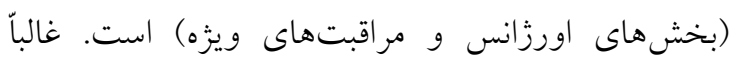

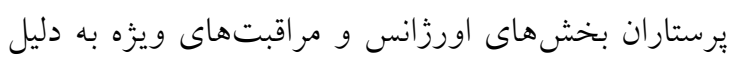

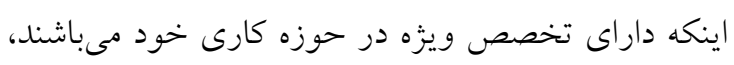

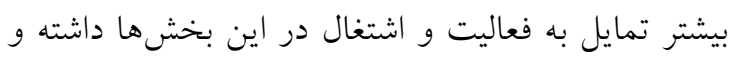
از فعاليت در اين بخشها احساس رضايت بيشترى دارند؛ جنانكه در اين مطالعه اكثريت برستاران بخش محل كار

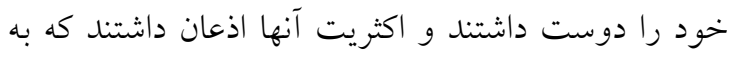
اجبار برستار بخشهاى فعلى نشدهاند و خود در انتخاب بخشهاى فعلى نقش داشتهاند. اين دلايل مىتواند به يرستاران در تطابق خود با شرايط و فعاليتهاى كارى تحت زوركويى كم محيط كار كمك بسزايى كند. نتايج اين مطالعه نشان داد ميانخين كل شكاف برون بين دسته

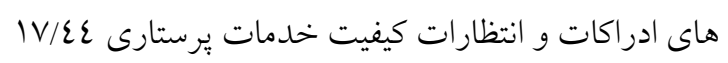

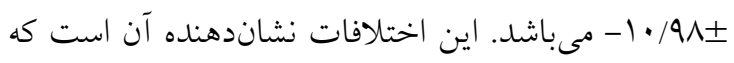

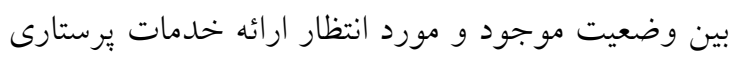

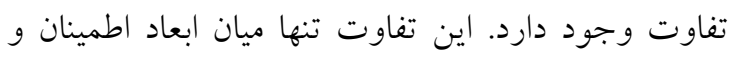
تضمين كيفيت خدمات برستارى ديده شد. نتايج مطالعه حاضر در برخى ابعاد همسو با مطالعه استكى در اصفهان

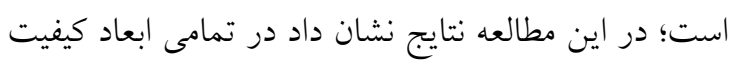

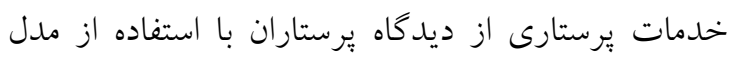

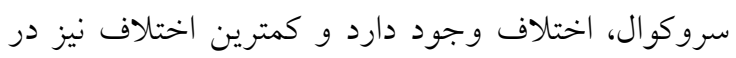

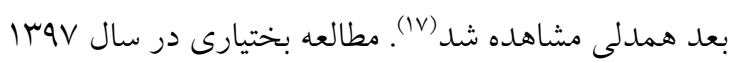
در زنجان نيز نتايج مشابهى داشته است. در اين مطالعه نيز در تمامى ابعاد، شكاف معنىدارى در كيفيت خدمات

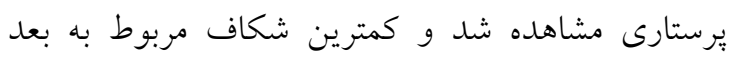

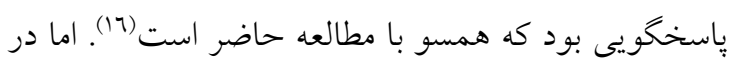
مطالعه ابراهيميان در فلاورجان اصفهان بيشترين شكاف در بران بهر

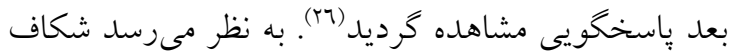

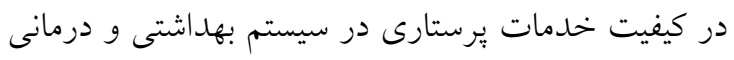

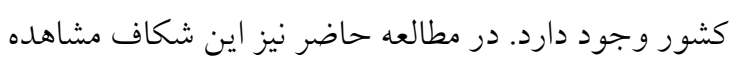

\section{بحث و نتيجه كيرى}

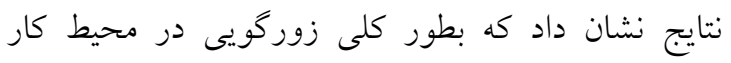

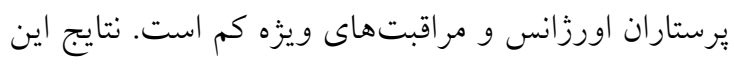

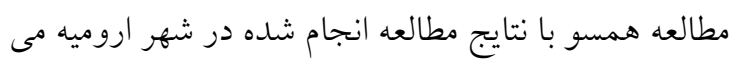
باشد. در اين مطالعه كه بر روى 17 إيرستار جهار

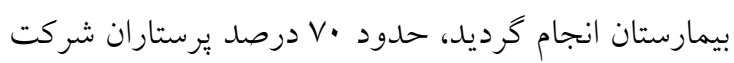

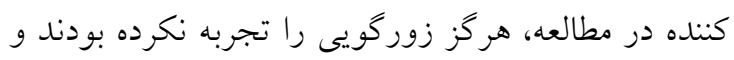

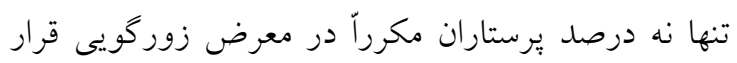

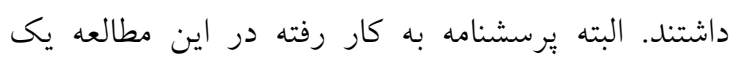

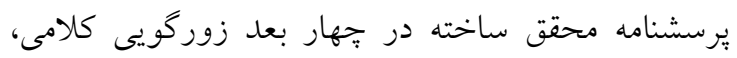

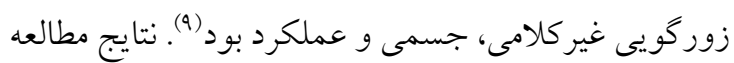
حاضر، مغاير با نتايج بيشتر مطالعات در ساير كشورهاست ونئ.

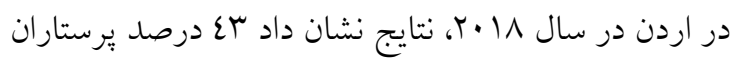
اردنى زوركويى شديد را تجربه نمودهاند (عَ). نتايج مطالعه

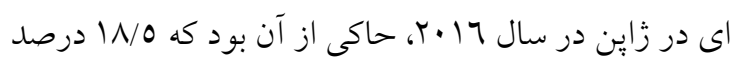

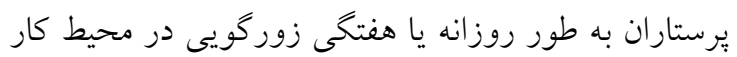

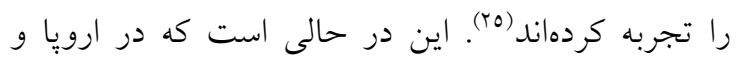
آمريكا، آمار و ابعاد زورگويى متفاوت خزارش شده است است.

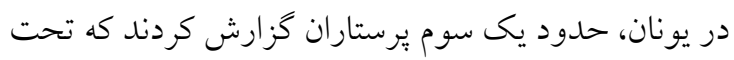

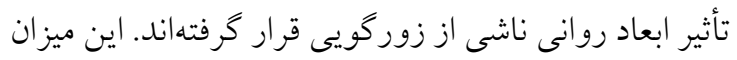

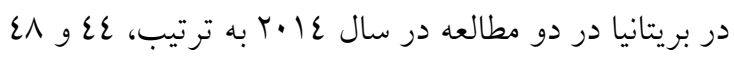

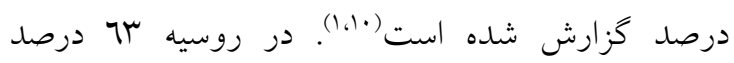

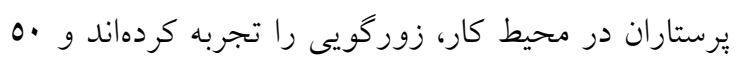

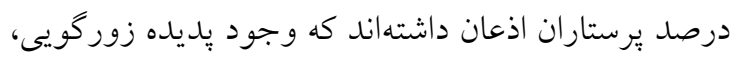

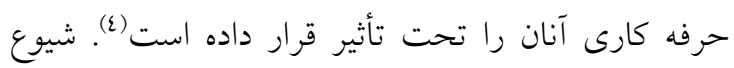

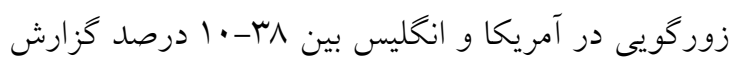

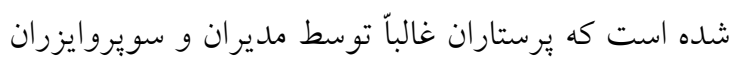
مورد زورگويى قرار مى گرفتند. به نظر مىرسد سيستمهاى بهداشتى و درمانى نقش مهمى مرونى

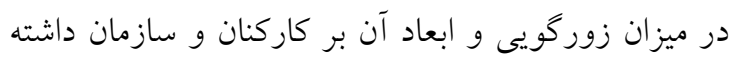
باشد. به طوريكه Obeidat در مطالعه خود اشاره مى كند كه نبود يك محيط كارى سازمانيافته، وظايف و حوزه

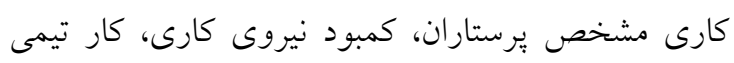
نامؤثر و عدم وجود سياستهاى روشن در زمينه بيشخيرى 
يكى از محدوديتهاى اين مطالعه استفاده از روش

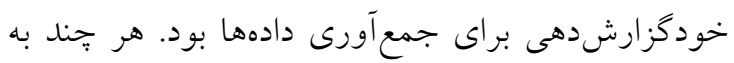

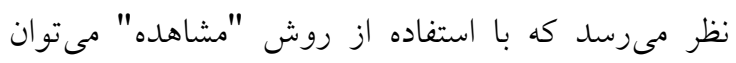

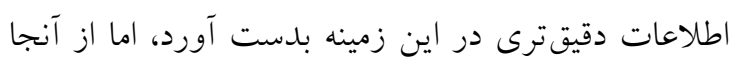

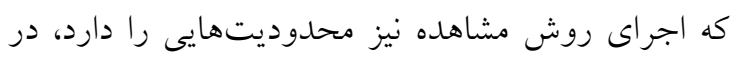

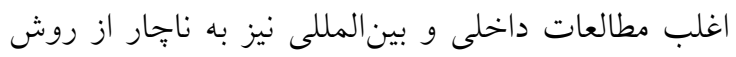
خودخزارشدهى براى جمعآورى دادهها در اين زمينه استفاده شده است. از محدوديتهاى ديخر مطالعه، نمونه

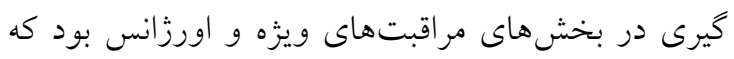

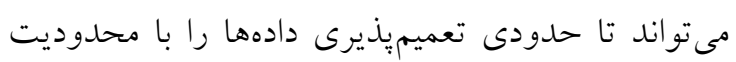

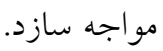
كر زجه نتايج اين مطالعه حاكى از ميزان شيوع بايين

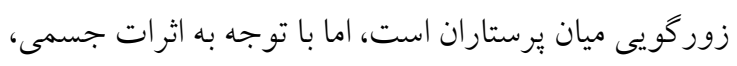

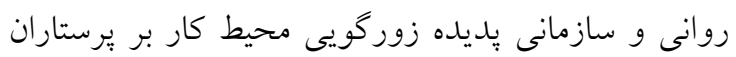

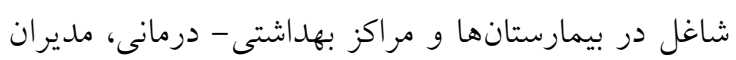

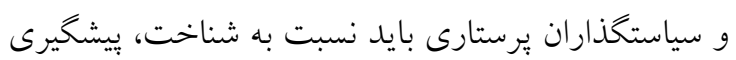

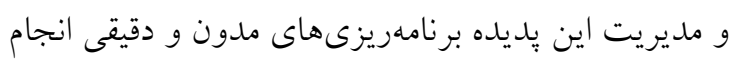

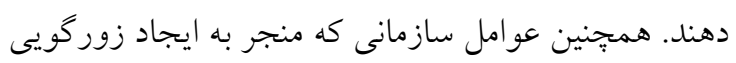

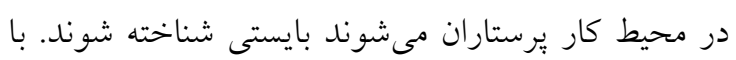

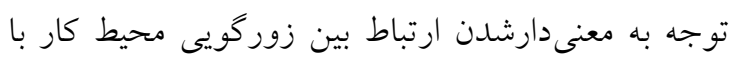

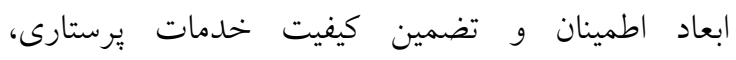

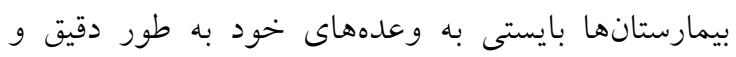

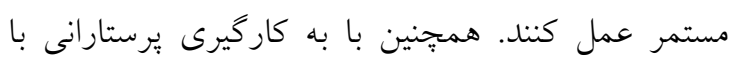
دانش و مهارت، حس اعتماد و اطمينان در بيمار ايجاد كنند. اين مطالعه نشان داد، هر جهه ميزان زوركويى محيط كار كم باشد، كيفيت خدمات يرستارى بالاتر است. بنابراين

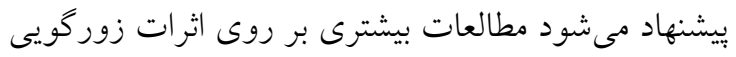

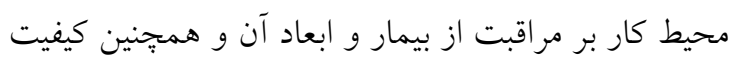

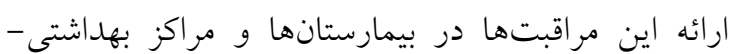

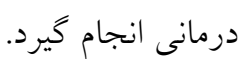

تعارض منافع: هيج گونه تعارض منافع توسط نويسندگان بيان نشده است.
شد. تفاوتها در اين حوزه بيشتر مربوط به ابعاد كيفيت

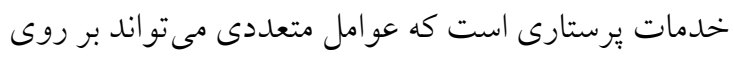

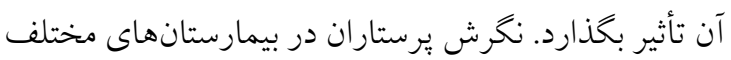

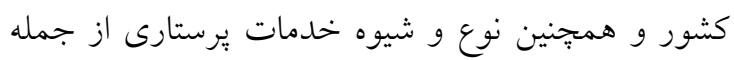
اين عو امل هستند؛ به طوريكه به نظر مىرسد در در بيمارستان

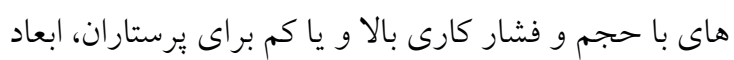
كيفيت خدمات يرستارى با تفاوتهايى همر اه مىباشد. نتايج اين مطالعه همجنين نشان داد تقريباً ميان همه ابعاد

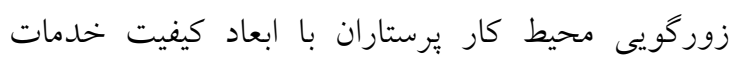

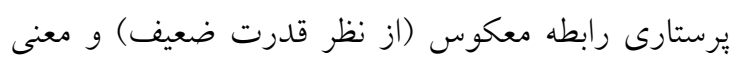
دارى وجود دارد. بطوريكه هر مقدار زورگويى محيط كار كاهش مى يابد، كيفيت خدمات برستارى افزايش مى ديابد. اين بدين مفهوم است كه هركاه زوركويى محيط كار

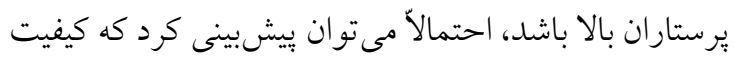

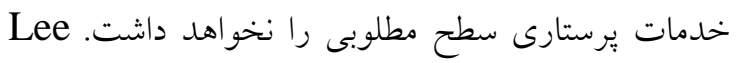

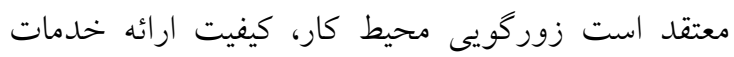
يرستارى و خودينداره حرفهاى را تهديد مى كند و و بايد

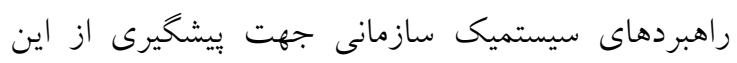

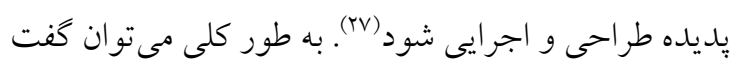

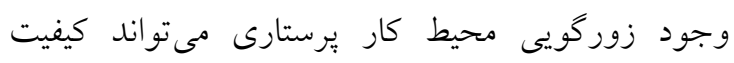

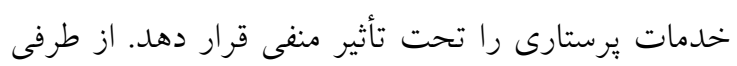

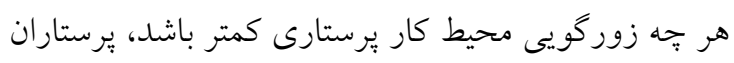

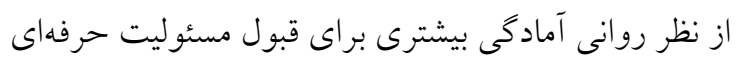
خو اهند داشت و بدين ترتيب كيفيت شغلى ارتقاء مى يابد. همجنين اين موضوع مى تو اند در ايجاد حس حرفهاى كرايى و اعتبار بخشيدن به آن نقش بسز ايى داثته باشد. در مقابل،

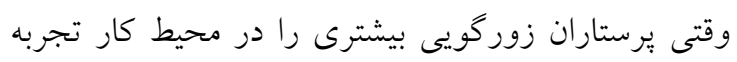

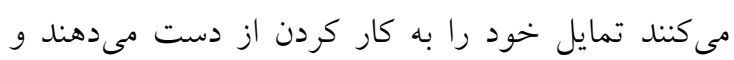
تحمل كمترى در مقابل بيماران دارند. بيشنهاد مى خردي

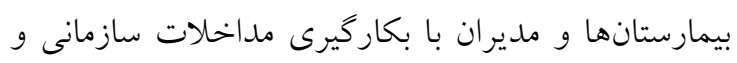

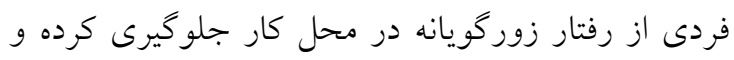

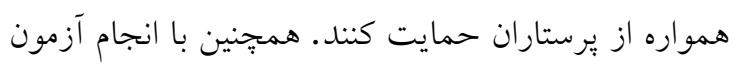
هاى روانشناسى در زمان استخدام از ورود افر ادى كه رفتار زورگ زيانه دارند جلو گيرى به عمل آورند. 


$$
\begin{aligned}
& \text { بيمارستانى امام خمينى (ره) بابت تسهيل در اجراى يزوهش }
\end{aligned}
$$

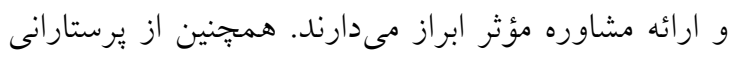

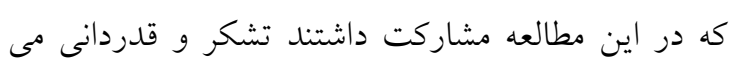

$$
\begin{aligned}
& \text { كردد. }
\end{aligned}
$$

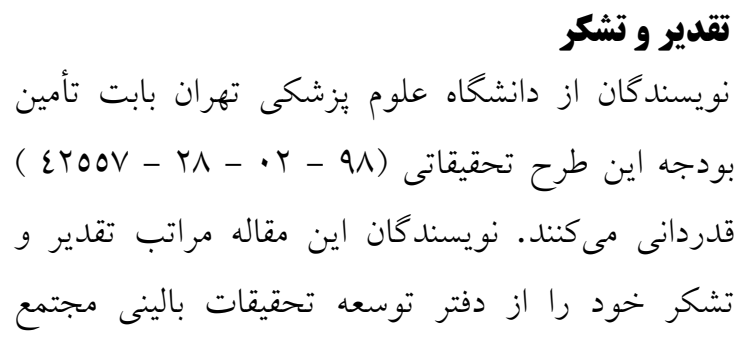

\section{References}

1. Hogh A, Baernholdt M, Clausen T. Impact of workplace bullying on missed nursing care and quality of care in the eldercare sector. Int Arch Occup Environm Health. 2018;91(8):963-70.

2. Johnson SL. International perspectives on workplace bullying among nurses: a review. Int Nurs Rev. 2009;56(1):34-40.

3. Wright W, Khatri N. Bullying among nursing staff: Relationship with psychological/behavioral responses of nurses and medical errors. Health Care Manag Rev. 2015;40(2):139-47.

4. Difazio RL, Vessey JA, Buchko OA, Chetverikov DV, Sarkisova VA, Serebrennikova NV. The incidence and outcomes of nurse bullying in the Russian Federation. Int Nurs Rev. 2019;66(1):94103.

5. Parchment J, Andrews D. The incidence of workplace bullying and related environmental factors among nurse managers. J Nurs Admin JONA. 2019;49(3):132-7.

6. Wolf LA, Perhats C, Clark PR, Moon MD, Zavotsky KE. Workplace bullying in emergency nursing: Development of a grounded theory using situational analysis. Int Emerg Nurs. 2018;39:339.

7. Yildırım D. Bullying among nurses and its effects. Int Nurs Rev. 2009;56(4):504-11.

8. Lucena PL, Costa SF, Batista JB, Lucena CM, Morais GS, Costa BH. Scientific production on workplace bullying and nursing: a bibliometric study. Rev Escola Enferm USP. 2018;52.

9. Esfahani AN, Shahbazi G. Workplace bullying in nursing: The case of Azerbaijan province, Iran. Iranian journal of nursing and midwifery research. 2014;19(4):409. [Persian]

10. Karatza C, Zyga S, Tziaferi S, Prezerakos P. Workplace bullying among the nursing staff of Greek public hospitals. Workplace health \& safety. 2017;65(2):57-64.

11. Karatza C, Zyga S, Tziaferi S, Prezerakos P. Workplace bullying and general health status among the nursing staff of Greek public hospitals. Ann General Psych. 2016;15(1):1-7.

12. Fang L, Hsiao LP, Fang SH, Chen BC. Effects of assertiveness and psychosocial work condition on workplace bullying among nurses: A cross-sectional study. Int J Nurs Prac. 2020;11:e12806.

13. Murray JS. Workplace bullying in nursing: A problem that can't be ignored. Medsurg Nursing. 2009;18(5):273-6.

14. Lu F, Xu Y, Yu Y, Peng L, Wu T, Wang T, Liu B, Xie J, Xu S, Li M. Moderating effect of mindfulness on the relationships between perceived stress and mental health outcomes among Chinese intensive care nurses. Frontiers in psychiatry. 2019;10:260.

15. Nasiripour A, Motaghi M. Nursing Care Quality and its Association with Process Management in Beheshti Hospital of Kashan in 2014 Shahid. Hospital. 2015;14(4):103-14. [Persian]

16. Bakhteari Z, Hanifi N, Amini K, Jafari Varjoshani N. Quality of Nursing Services in Dialysis Center of Valiasr Hospital in Zanjan from Nurses and Patients' Viewpoint Using the SERVQUAL Model. Iran Journal of Nursing. 2018;31(113):18-29. [Persian]

17. Esteki R, Attafar A. Quality of nursing services (contemporary level of reality and level of expectation) from nurses' viewpoint on the basis of SERVQUAL Model in Al-Zahra Hospital in Isfahan (2010). Modern Care Journal. 2012;9(2). [Persian]

18. Laschinger HK. Impact of workplace mistreatment on patient safety risk and nurse-assessed patient outcomes. JONA: J Nurs Admin. 2014;44(5):284-90.

19. Dang D, Bae SH, Karlowicz KA, Kim MT. Do clinician disruptive behaviors make an unsafe environment for patients?. J Nurs Care Qua. 2016;31(2):115-23. 
20. Einarsen S, Hoel H, Notelaers G. Measuring exposure to bullying and harassment at work: Validity, factor structure and psychometric properties of the Negative Acts Questionnaire-Revised. Work \& stress. 2009;23(1):24-44.

21. Alipour A, Dianat I, Halvani GH, Falah Zadeh H. Individual and job factors affecting the exposure to occupational violence among health care workers in the hospitals in Yazd province in 2016. Health and Safety at Work. 2018;8(2):175-86. [Persian]

22. Salimi H, Firozjaie AM, Najarpourian S, Ziaaddini Z, Fini AA, Yousefzadeh M. Investigation of Bullying and Harassment in the Workplace Using the Psychometric Properties of the Negative Acts Questionnaire-Revised (NAQ-R) in Nurses. Qom University of Medical Sciences Journal. 2019;12(11):60-9. [Persian]

23. Parasuraman A, Zeithaml VA, Berry LL. Servqual: A multiple-item scale for measuring consumer perc. Journal of retailing. 1988;64(1):12.

24. Obeidat RF, Qan'ir Y, Turaani H. The relationship between perceived competence and perceived workplace bullying among registered nurses: A cross sectional survey. Int J Nurs Stud. 2018;88:718.

25. Yokoyama M, Suzuki M, Takai Y, Igarashi A, Noguchi-Watanabe M, Yamamoto-Mitani N. Workplace bullying among nurses and their related factors in Japan: a cross-sectional survey. J Clin Nurs. 2016;25(17-18):2478-88.

26. Ebrahimian T, Salehi A, Rejalian F, Jabbari A. Evaluation of the Nursing Services Quality from the Patient Perspective by Using the Kano and SERVQUAL Combines Model. Health Research. 2017;2(2):117-23.

27. Lee EM, Kim DH. Moderating effects of professional self-concept in relationship between workplace bullying and nursing service quality among hospital Nurses. J Kor Acad Nurs Admin. 2018;24(5):375-86. 